\title{
Effect of non-structural masonry brick infill walls on the robustness of a RC framed building severely damaged due to a landslide
}

\author{
Mariana Barros ${ }^{\mathbf{a}}$, Eduardo Cavaco ${ }^{\mathbf{b}}$, Luís Neves ${ }^{\mathbf{c}}$, Eduardo Júlio $^{\mathbf{d}}$
}

\begin{abstract}
Western countries are increasingly demanding for robust structures, i.e., structures capable of withstanding local damage caused by unforeseen extreme events without triggering a progressive collapse, thus reducing the magnitude and proportion of the resulting consequences.
\end{abstract}

In this paper, the robustness of framed RC buildings is analysed by comparing the reliability of the damaged structure with that of the original structure and considering (or not) the contribution of the masonry infill walls. To validate the adopted methodology, this is tested on a residential RC building severely damage due to a landslide, herein considered as case-study. A numerical model of the original, as well as, of the damaged structure is defined using force-based finite elements with distributed plasticity. Masonry infill walls are modelled as equivalent internal struts. Monte Carlo simulation and FORM coupled with artificial neural networks and response surface polynomials are used in parallel to perform the reliability analyses of both original and damaged structures. Obtained results show that the masonry infill walls are fundamental to contain damage progression after the failure of a couple of columns. In fact, without these non-structural elements, the structure would lack in robustness, and the probability of failure would be above $99 \%$. On the contrary, by considering the structural contribution of the masonry infill walls, the robustness of the structure would be circa of $30 \%$ corresponding to a failure probability of $6 \%$.

Keywords: Robustness; Reliability; Probability of Failure; Reinforced Concrete; Masonry Infill Walls; Damage; Progressive Collapse.

\footnotetext{
${ }^{a}$ FCT - Universidade NOVA de Lisboa, Almada, Portugal

${ }^{\mathrm{b}}$ CERIS, FCT - Universidade NOVA de Lisboa, Almada, Portugal

${ }^{c}$ NTEC, Dept. of Civil Engineering, University of Nottingham, Nottingham, United Kingdom

${ }^{\mathrm{d}}$ CERIS, Instituto Superior Técnico, Universidade de Lisboa, Portugal

* Corresponding author, email: e.cavaco@fct.unl.pt
} 


\section{Introduction}

\subsection{Background}

The interest on structural robustness has increased in the past 40 years, due to the occurrence of unforeseeable extreme events with resulting unacceptable consequences on structures and with high impact on society. The case of the partial collapse of the Ronan Point Building $(U K, 1968)[1]$ or the case of the total collapse of the World Trade Center (NY, 2001) [2], among other examples, have increased the discussion on the importance of structures to withstand inflicted local damages without triggering progressive collapse, thus resulting in disproportionate and catastrophic consequences.

\subsection{Research significance}

Taking into account the above-mentioned reasons, today it is mandatory to perform a structural robustness analysis for both new and existing structures. Special concern should be devoted to certain structural types, recognized as lacking in robustness (e.g., the Larsen-Nielson building system [1] used in Ronan Point), or structures erected on a specific period related to poor quality of construction, as it is the case of a significant percentage of reinforced concrete (RC) framed buildings erected in Portugal between the 70's and the 90's [3].

In spite of the relevance of structural robustness, current codes and standards do not have a comprehensive approach for robustness, lacking in methods to check and/or to design for robustness. However, experience has shown that certain types of structures, although not having been specifically designed for robustness, exhibit an intrinsic capacity to withstand severe local damage without collapsing. This is the case of framed RC buildings with masonry infill walls which, although designed as nonstructural elements, are capable of materializing struts that, combined with the RC frame, may provide extra strength to both horizontal and vertical actions.

\subsection{Approach}

A generic robustness analysis capable of considering a generic multi-story building subjected also to a generic and wide range of damage scenarios is unrealistic and simply not possible [4]. This paper presents a robustness analysis approach for multi-story RC framed buildings subjected to severe damage, based on the comparison of the reliability of the damaged and intact structure. The structure reliability is evaluated using advanced non-linear numerical models coupled with both simulation and gradient based reliability methods. Non-linear numerical models are rarely used on reliability studies. However, they are of 
paramount importance in order to capture the potential alternate load paths developed during a structure failure analysis.

To depict the proposed approach, a 16 stories residential RC building, that experienced a local failure of a set of three columns at the ground level, after a landslide, is analysed. The structure inspection and retrofitting was already discussed in [3].

\section{Literature Review}

According to Murty and Jain [5] masonry infill walls in RC buildings may cause different undesirable effects under seismic loading, such as short-column effect, soft-story effect, torsion, and out-of-plane collapse. However, beneficial effects are reported in [5]-[7], including increase lateral stiffness and strength. Additionally, if appropriate reinforcement arrangements are provided in the masonry, and properly anchored into the $\mathrm{RC}$ frame, an out-of-plane response improvement may also be achieved. The configuration and presence of masonry infills significantly change the collapse mechanism.

The reported undesirable effects are mostly related to partially infilled frames and non-uniform distribution, in height and/or in plan, of such infills in buildings. Masonry fully infilled frames have been shown to have better seismic performance and lower collapse risk when compared to bare frames [7]. In the experimental tests conducted by Pujol et. al [8], consisting of full-scale 3-story flat-plate structure strengthened with masonry infill walls and tested under displacement reversals, infill walls were effective in increasing the strength (by 100\%) and stiffness (by 500\%) of the original and bare RC structure. The single story frames under in-plane lateral forces tested by Abdel-Hafez et al. [9] show that the presence of masonry infill walls changed the behaviour of the bare $\mathrm{RC}$ frame to a shear wall behaviour increasing the capacity by approximately $100 \%$. Similar conclusions related to infilled frames strength and stiffness can be drawn from the experimental work conducted by Al-Chaar [10].

Regarding strategies to model the behaviour of infilled frames, extensive research has been dedicated to the topic [11]-[20]. Micro and macro models have been investigated. For the later, centered or eccentric struts or multi-struts have been proposed, validated by experimental work and numerical simulations.

In addition to the resistance to horizontal actions, namely to the seismic action, masonry infill walls have also demonstrated a positive influence on the behaviour of RC buildings severely damaged locally, such as in the case of the failure of a column or a set of columns [21]-[25]. However, research addressing this 

issue is scarce and mostly numerical. The Unified Facilities Criteria (UFC) guidelines [26] of the Department of Defense of USA suggest that some comparisons can be established between the behaviour of RC frames submitted to e.g. the loss of a column and the behaviour of the same frames subjected to seismic actions. However, it must be noted that gravity loads are much different from seismic actions (base displacements) and that behaviour coefficients, widely used on seismic analysis and codes, are not valid in this context.

In the study conducted by Sasani (2008) [21], the response of a 6-story RC infilled frame structure was numerically evaluated following the simultaneous removal of two adjacent exterior columns. Threedimensional Vierendeel frame action of the transverse and longitudinal frames with the participation of the infill walls was identified as the major mechanism for redistribution of loads in the structure. The response of the structure due to additional gravity loads, in the absence of infill walls, was also evaluated, and results have shown that, while the maximum vertical displacement of the structure was increased by almost 2.4 times, the system could still avoid progressive collapse.

Xavier et al. [24] performed a pushdown analysis of a 7-story composite steel-concrete benchmark building under sudden column loss scenarios and concluded that the use of masonry infill panels for building's envelope can considerably increase robustness.

A deterministic progressive collapse assessment following the Unified Facilities Criteria (UFC) guidelines [26] of the Department of Defense of USA was carried out for a typical 10-story RC framed structure by Helmy et al. [25]. Fully nonlinear dynamic analysis of the structure was carried out using the Applied Element Method following different damage scenarios such as the removal of a corner column, an edge column, an edge shear wall, internal columns and internal shear walls. It was found that neglecting the effect of the masonry infill walls conducts to incorrect structural behaviour assessment as they provide a valuable contribution in mitigating progressive collapse. Nevertheless, results indicate that the area of the opening has a significant effect on the wall's ability to resist the structure's collapse.

Tiago and Júlio (2010) [3] describe the inspection and assessment of a severely damaged RC residential building which withstood the loss of the first two levels of three external columns after a landslide caused by persistent heavy rain. These authors concluded that the masonry infill walls, acting as struts, combined with the slabs of the RC framed structure, acting as ties, have contained the building's progressive collapse. 
116 These works show that the masonry infills can provide alternative load paths to RC framed structures

117 subjected to vertical support(s) local failure. For this reason, to understand the performance of buildings

118 under severe damage scenarios, it is fundamental to evaluate their robustness analysis taking into account

119 secondary elements, in particular masonry infill walls. Although several robustness indicators have been

120 proposed in the literature [26], the probabilistic approach for robustness quantification proposed in [27]

121 suits this purpose as it is given by the ratio between the reliability index of the damaged structure, $\beta_{d}$,

122 and the reliability index of the undamaged structure, $\beta_{i}$ :

$R=\frac{\beta_{d}}{\beta_{i}}$

where:

$\beta=-\Phi^{-1}\left(P_{f}\right)$

and $\Phi()$ is the normal distribution and $P_{f}$ is the probability of failure. The maximum robustness, $R$,

126 computed according to Equation (1) can be 1, if the probability of failure of the damaged and undamaged structure is the same. This means that the damage inflicted has null impact on structural safety, which rarely occurs. The robustness index results null $(R=0)$ when the probability of failure of the damaged structure is exactly $50 \%$. If this probability is above $50 \%$, negative values can be expected when

130 computing Equation (1), meaning that robustness is even lower. However, this distinction is not meaningful, since in the domain of structural engineering, probabilities within this range are considered extremely high and unacceptable, considering the possible consequences of a structural failure.

\section{Case Study}

\subsection{Description of the accident}

135 In 2000, in Coimbra, Portugal, a landslide caused severe damage to the RC structure of a 16 stories residential building (Figure 1). The first two levels of three exterior columns were destroyed and the rear

137 body of the building supported by these, with a dimension in plant of $9.5 \times 6.7 \mathrm{~m}^{2}$, became a $7.0 \mathrm{~m}$ span 138 cantilever with 12 stories above (Figure 1 (b)). Unlike what would be expected, no significant anomalies were identified, other than cracks on the masonry infill walls with a maximum width of $2 \mathrm{~mm}$, located 

started (Figure $2(b))$.

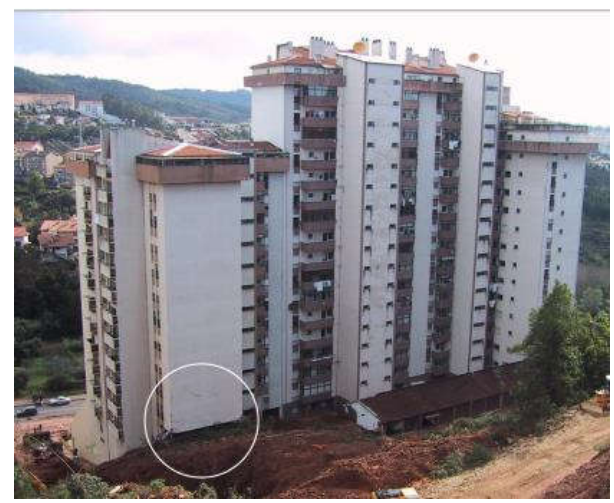

(a)

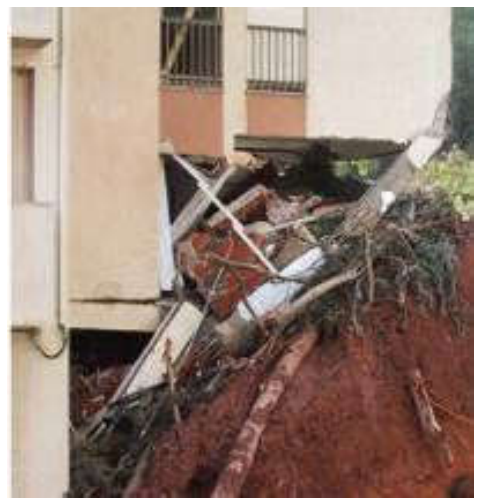

(b)

Figure 1 -Severely damaged RC residential building after a land slide: (a) rear façade; (b) collapse of the outer columns of the rear body of building.

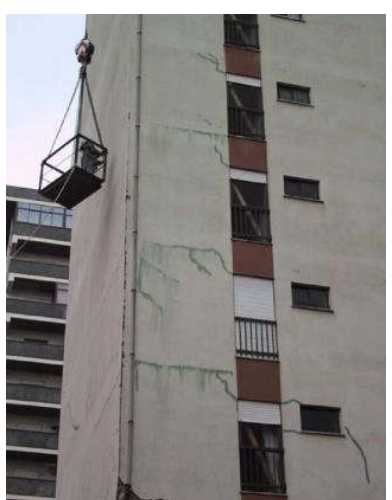

(a)

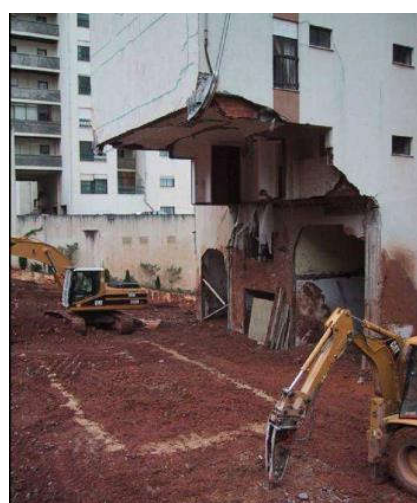

(b)

Figure 2 -Details of the accident: (a) cracks along the façade masonry infill walls; (b) removal of debris from the accident site.

144 According to [3], the progressive collapse of the structure was prevented due to the contribution of the 145 non-structural infill walls. More specifically, the gravity loads, initially supported by the destroyed outer

146 columns, were redistributed leading to the development of compressive stresses in the masonry infill 147 walls (struts) and tension stresses (ties) in the slabs. The equilibrium to the adjacent part of the structure 148 was ensured by a resultant tension force at the top slab, a resultant compressive force at the bottom slab, 149 and a resultant compressive force at the columns, as depicted in Figure 3. 


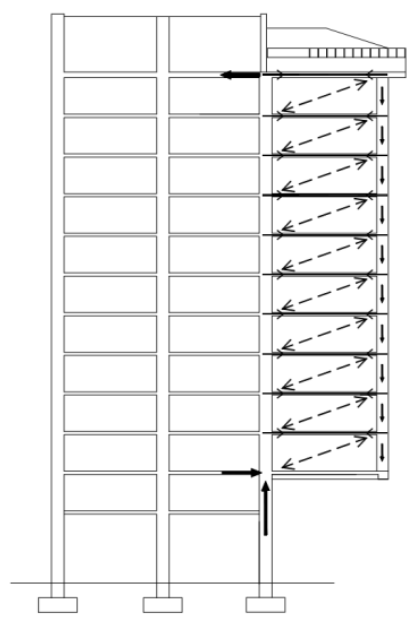

Figure 3 - Schematic drawing of the strut-tie system developed on the façade masonry infill walls and flooring slabs.

151 Cachado et al. [22] performed a 3D FEM analysis of the damaged structure either neglecting the 152 structural contribution of the masonry infill walls or considering it as shell elements. Following the frame analysis, the authors have concluded that the failure mechanism of the rear body was controlled by the cantilever beams since their flexural capacity was largely exceeded for the probable acting loads. Results of the frame plus infill analysis showed the development of alternative load paths through a strut-tie system, only possible due to the contribution of masonry infill walls. In this case, both the cantilever beams, who acted as ties, and the masonry infill walls, who played the struts' role, did not exceed their bearing capacity and the damaged structure was able to sustain the estimated acting loads.

\subsection{Structural characterization}

As already mentioned, the building has a RC framed structure settled on direct foundations. The floorings are composed of ceramic blocks, supported by precast pre-stressed concrete joists, and topped by a cast "in-situ" concrete layer (Figure 4). This type of flooring is typically limited to low-rise buildings, due to deficient diaphragm effect, which tends to result in poor seismic behavior. A more detailed description of the structure is presented next, although limited to the rear body of the building, that subjected to extended damages after the landslide.

The arrangement of the structural elements per story is shown in Figure 5. The concrete joists are supported by the V1 and V5 beams and spaced $0.33 \mathrm{~m}$ apart. Ceramic blocks with $0.20 \mathrm{~m}$ of height are placed in the middle of the joist and topped by a cast in-situ concrete layer with $0.04 \mathrm{~m}$ of thickness. The concrete layer is reinforced with $8 \phi 6 / \mathrm{m}$ on both directions and over reinforced with $8 \phi 8 / \mathrm{m}$ in the joist 


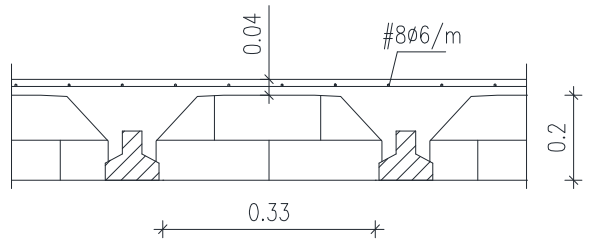

(a)

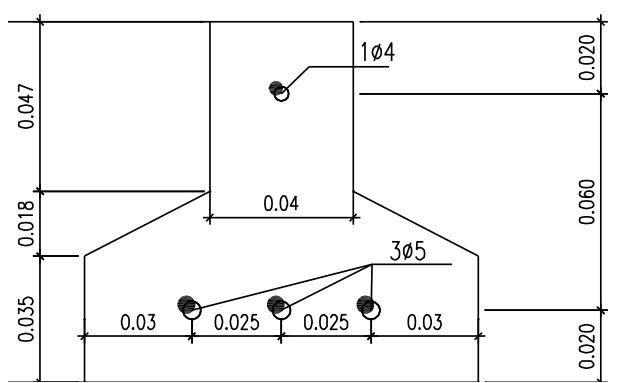

(b)

Figure 4 -Building flooring system (dimensions in m): (a) schematic drawing; (b) precast and pre-stressed concrete joist.

Beams V1 and V5 present a cross-section of $450 \times 600 \mathrm{~mm}^{2}$ but the number and diameter of reinforcing bars is unknown. Beams V2 and V4 have a cross-section of $300 \times 350 \mathrm{~mm}^{2}$. The top reinforcement is composed by 4 bars with $12 \mathrm{~mm}$ of diameter, while bottom correspond to 4 bars with $10 \mathrm{~mm}$ of diameter.

The corner columns, P1, P3, P4 and P6 have a cross-section of $300 \times 600 \mathrm{~mm}^{2}$ and 8 rebars with $16 \mathrm{~mm}$ of diameter. The central columns, P2 and P5, have a cross-section of $300 \times 700 \mathrm{~mm}^{2}$ with 10 rebars with $16 \mathrm{~mm}$ of diameter. According to the project, C20/25 concrete class and S400 steel grade have been adopted, as usual at that time and place.

Both façade and partition walls were built using ceramic bricks connected and plastered with a cementitious mortar. Façade walls and partition walls present a height of $2300 \mathrm{~mm}$, being the formers composed by double masonry panels with a thickness of $300 \mathrm{~mm}$, and the latter composed by single masonry panels with a thickness of $150 \mathrm{~mm}$. There are two opening in the façade walls supported by the V2 and V4 beams with the dimensions of $2100 \times 1000 \mathrm{~mm}^{2}$ and $1100 \times 1000 \mathrm{~mm}^{2}$ (see Figure 1) and $2 \times 2100 \times 1000 \mathrm{~mm}^{2}$ (see Figure 2), respectively 


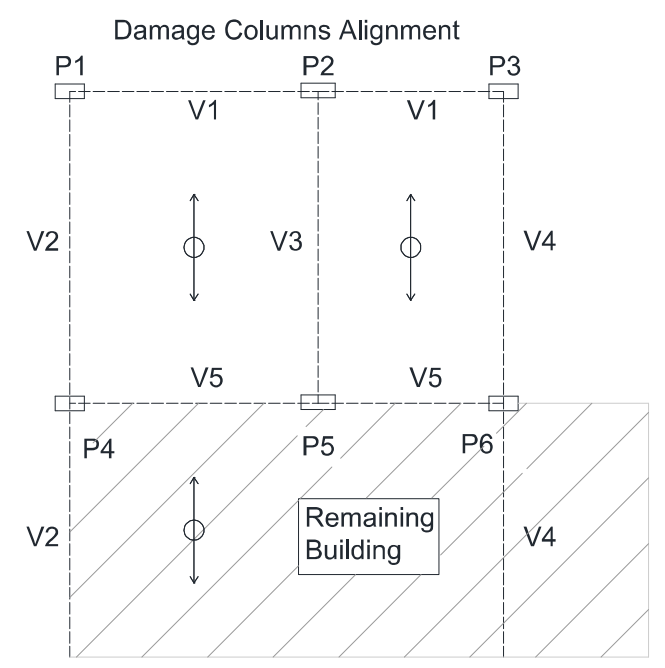

Figure 5 - Schematic drawing of the elements' arrangement on a typical floor plan of the damaged body.

\subsection{Numerical Model}

A non-linear numerical model of both the original structure and the damaged structure was developed using OpenSees [28] aiming at performing a reliability analysis to characterize the structure prior and after the accident. The event exact moment and the respective dynamic effects were, in this manner, not considered in this paper. In the first case, the contribution of the masonry infill walls for structural purposes was neglected, as this is the common practice in the design of framed $\mathrm{RC}$ structures. In the second case, the masonry infill walls were first neglected and then taken into account, in order to distinguish their impact on the structure's safety. The numerical model was limited to the rear body of the building since, as according to Cachado et al. [22], collapse is controlled by the failure of the cantilever beams (V2 and V4). Since the cantilevers are structurally isostatic, limiting the numerical model to the rear body, and neglecting the deformation of the rest of the building, does not have relevant influence on the structural strength, if rigid body global stability problems are disregarded.

On the numerical models of both the original (undamaged) structure and the damaged structure, forcebased frame elements were used to simulate the behaviour of beams and columns. The respective cross sections were discretized into multiple fibres for which a constitutive relation was assigned according to the type of material.

The structural effect of floorings was indirectly considered: the corresponding self-weight, including the remaining dead and live loads, were applied directly to the V1 and V5 beams; on the damaged model of the structure, the bending strength of the flooring system was neglected and only its tying effect, 
211 described by [3], was considered and simulated using an equivalent tie at V2 and V4 levels, as foreseen in

212 [26]. The flooring contribution to the tie effect was yet limited to a flooring band of $1 \mathrm{~m}$ width next to V2

213 and V4 beams, as already considered by [3] and recommended in [26].

214 This simplifying, however conservative hypothesis, was adopted to reduce the number of structural 215 members to be modelled and, ultimately, to allow the reliability analysis to be performed. In the case of

216 V1 and V5 beams, the area of the reinforcing bars had to be estimated based on REBAP [29], the

217 prevailing legislation at that time, due to missing information.

218 Karsan-Jirsa [26] constitutive model was used to simulate the concrete behaviour, whereas for the

219 reinforcing bars a uniaxial bilinear model with zero strain-hardening ratio was considered.

220 The contribution of the masonry infill walls was accounted for using the eccentric strut model proposed 221 by Al-Chaar [1]. Although many other models have been proposed in the literature, this approach was 222 selected since: it is computationally little time consuming; it is strongly supported by extensive 223 experimental campaign; it has been defined based on the experiments of RC frames, while on other 224 proposal steel frames have been used. However, and since this model was developed for horizontal loads, for the case study herein addressed it is necessary to adapt first the model for vertical loads, as suggested in the UFC manual [25]. In the original model, as shown in Figure 6 (a), the forces transmitted by the masonry infill walls are assumed to be resisted by the columns and the equivalent strut is connected to the column at a distance $L_{c}$ from the face of the beams. The strut width, $a$, is dependent on the relative

229 bending stiffness of the columns and the masonry panel, $\lambda H$. The distance, $L_{c}$, represents the length 230 needed for the development of plastic hinges and is determined geometrically considering the strut width and the angle of the diagonal strut. The columns segments with length, $L_{c}$, are modelled as rigid to take into account the effect of the masonry panel. 


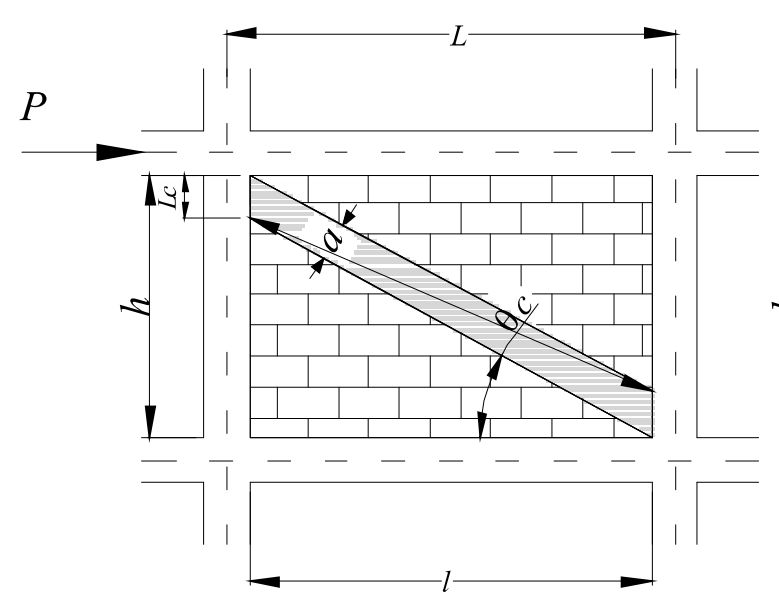

(a)

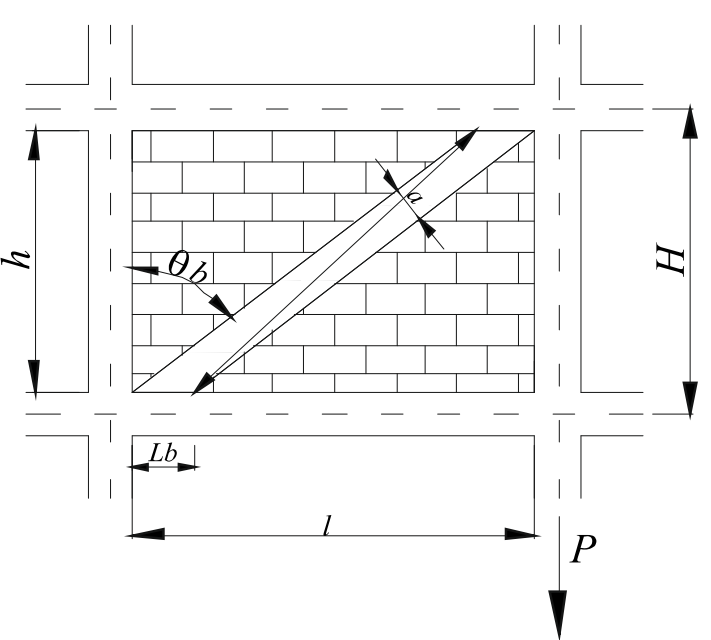

(b)

Figure 6 - Eccentric strut model proposed by Al-Chaar: (a) for lateral loads; (b) adapted for vertical loads.

234 For vertical actions, it is assumed that the load is distributed between the beams, instead of between the

236 the beams positioned at a distance, $L_{b}$, from the edge of the columns, as depicted in Figure 6 (b). In this

case, the strut width, $a$, is dependent on the relative stiffness of the beams and masonry wall, $\lambda L$ :

$a=0.175 D(\lambda L)^{-0.4}$

$\lambda L=L \sqrt[4]{\frac{E_{m} t \sin \left(2 \theta_{b}\right)}{4 E_{c} I_{\text {beam }} l}}$

where $L$ is the span, assumed as the distance between the columns midlines, $l$ is the width of the

$L_{c}=\frac{a}{\cos \left(\theta_{c}\right)}$

$L_{b}=\frac{a}{\sin \left(\theta_{b}\right)}$ 


$$
\begin{aligned}
& \tan \left(\theta_{c}\right)=\frac{h-L_{c}}{l} \\
& \tan \left(\theta_{b}\right)=\frac{h}{l-L_{b}}
\end{aligned}
$$

244 To take into account the effect of the openings, the strut width should be reduced to $a_{\text {red }}$, through a

245 reduction factor $[1], R_{1}$, depending on the ratio between the area of the opening, $A_{\text {open }}$, and the total area 246 of the panel, $A_{\text {panel }}$ :

$$
\begin{aligned}
& a_{\text {red }}=a \times R_{1} \\
& R_{1}=0.6\left(\frac{A_{\text {open }}}{A_{\text {panel }}}\right)^{2}-1.6 \frac{A_{\text {open }}}{A_{\text {panel }}}
\end{aligned}
$$

247 The failure of the strut is controlled by the compressive or the shear strengths of the masonry. The strut 248 maximum strength is [1]:

$$
\begin{aligned}
& R_{\text {strut }}=\min \left\{\begin{array}{c}
R_{c r}=a \times t \times f_{m}^{\prime} \\
R_{\text {shear }} / \cos \theta_{\text {strut }}=A_{n} \times f_{v}^{\prime} / \cos \theta_{\text {strut }}
\end{array}\right\}=\min \left\{\begin{array}{c}
R_{c r}=a \times t \times f_{m}^{\prime} \\
A_{n} \times f_{v}^{\prime} / \cos \theta_{\text {strut }}
\end{array}\right\} \\
& \tan \theta_{\text {strut }}=\frac{h-2 L_{c}}{l}
\end{aligned}
$$

249 where $\theta_{\text {strut }}$ is the angle between the eccentric strut and the horizontal, $R_{c r}$ and $R_{\text {shear }} / \cos \theta_{\text {strut }}$ are the 250 compressive and shear strength of the equivalent strut, respectively, and $f_{m}^{\prime}$ and $f_{v}^{\prime}$ are the compressive and the shear strength of the masonry, respectively.

252 Figure 7 shows the numerical model of the rear body of the damaged structure considering the effect of 253 the masonry infill walls. For the case where this effect has been neglected, neither the masonry equivalent struts nor the rigid elements, shown in Figure 7, were considered. In the original undamaged model of the

255 structure, the outer columns were extended up to the foundations and the masonry equivalent struts were 

conducted.

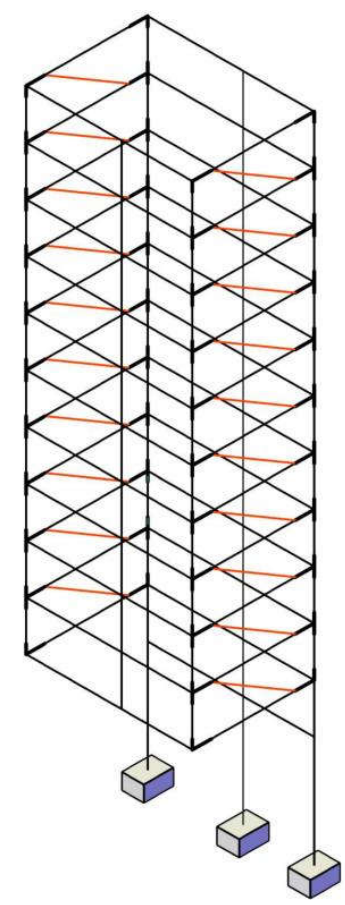

(a)

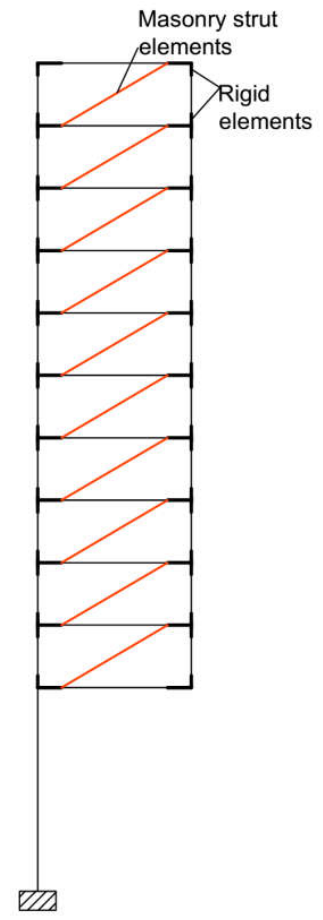

(b)

Figure 7 -Numerical model of the rear body of the damaged building: (a) 3D perspective; (b) lateral view.

\section{RELIABILITY ANALYSIS}

\subsection{Random variables characterization}

263 The uncertainties related to the strength of concrete, steel, and masonry were considered in their characterization from a probabilistic point of view, following the recommendations of the JCSS

265 Probabilistic Model Code [30]. The concrete compressive strength, $f_{c}$, was modelled as a lognormal distribution with a mean value of $28 \mathrm{MPa}$ (for a C20/25 concrete grade), and a coefficient of variation

$267(\mathrm{CoV})$ of $15 \%$, which results into a standard deviation of $4.2 \mathrm{MPa}$. The yielding stress of steel, $f_{y}$, was modelled as normally distributed, with a mean value equal to $S_{n o m}+2 \sigma \mathrm{MPa}$, where $S_{n o m}$ is the nominal yielding stress, and $\sigma$ is the standard deviation $(30 \mathrm{MPa})$. For an $\mathrm{S} 400$ steel grade, $S_{\text {nom }}$ can be 
considered equal to $400 \mathrm{MPa}$ and the mean yielding stress results equal to $460 \mathrm{MPa}$. The compressive

271 strength of the masonry wall, $f_{m}$, according the Probabilistic Model Code is defined by:

$$
f_{m}=f_{m}^{\prime} Y_{1}
$$

272 where $Y_{I}$ is a a lognormal variable with a mean equal to 1.0 and a $\mathrm{CoV}$ of $17 \%$. For this case study, the

273 mean value of the masonry compressive strength, $f_{m}^{\prime}$, was considered equal to $13 \mathrm{MPa}$, as suggested in $274[31]$.

275 In what concerns the actions, four additional random variables were considered associated to the selfweight of RC elements and masonry walls and to the live loads. A normal distribution was assumed for 277 the concrete self-weight, $g$, with a mean value of $25 \mathrm{kN} / \mathrm{m}^{3}$ and a standard deviation of $0.75 \mathrm{kN} / \mathrm{m}^{3}$ [30]. 278 The self-weight of clay masonry walls, $g_{1}$, was modelled by a normal distribution with a mean value of $2792.9 \mathrm{kN} / \mathrm{m}^{2}$ and $\mathrm{CoV}$ of $5 \%$. Two types of live loads were considered according to the Probabilistic Model 280 Code: the sustained live load $q_{s}$, Gamma distributed with a mean value of $0.30 \mathrm{kN} / \mathrm{m}^{2}$, a standard deviation of $0.31 \mathrm{kN} / \mathrm{m}^{2}$ and renewal rate of one time each 7 years; and the intermittent live load $q_{i}$, of shorter duration, also described by a Gamma distribution with mean value of $0.30 \mathrm{kN} / \mathrm{m}^{2}$, a standard deviation of $0.36 \mathrm{kN} / \mathrm{m}^{2}$, and an average renewal time of 1 year and duration of 1 day.

Finally, a uncertainty related to the strength and actions models was considered, through two additional random variables: the uncertainty of the strength model, $\theta_{R}$, and the uncertainty of the actions models, $\theta_{E}$. Both uncertainties were admitted lognormally distributed with mean values of 1.2 and 1.0 , and standard deviations of 0.15 and 0.10 , respectively.

289 time with an average occurrence rate of one day per year; and the second corresponds to the isolated action of the sustained live load on the remaining 364 days of the year.

291 The remaining variables were assumed as deterministic due to their relatively low impact on structural safety. The random variables, distributions, and parameters considered are summarized in Table 1. 
Table 1 - Random variables distributions and parameters

\begin{tabular}{lcccc}
\hline \multicolumn{1}{c}{ Random Variable } & & Distribution & $\begin{array}{c}\text { Mean } \\
\text { value }\end{array}$ & $\begin{array}{c}\text { Standard } \\
\text { deviation }\end{array}$ \\
\hline Concrete strength & $f_{c}(\mathrm{MPa})$ & lognormal & 28.0 & 4.2 \\
Steel strength & $f_{y}(\mathrm{MPa})$ & normal & 460.0 & 30.0 \\
Masonry strength & $f_{m}(\mathrm{MPa})$ & lognormal & 13.0 & 2.21 \\
Concrete self-weight & $g\left(\mathrm{kN} / \mathrm{m}^{3}\right)$ & normal & 25.0 & 0.25 \\
Masonry self-weight & $g_{1}\left(\mathrm{kN} / \mathrm{m}^{2}\right)$ & normal & 2.9 & 0.15 \\
Sustained live-load & $q_{s}\left(\mathrm{kN} / \mathrm{m}^{2}\right)$ & gamma & 0.3 & 0.31 \\
Intermittent live-load & $q_{i}\left(\mathrm{kN} / \mathrm{m}^{2}\right)$ & gamma & 0.3 & 0.36 \\
Resistance model uncertainty & $\theta_{R}$ & lognormal & 1.2 & 0.15 \\
Load model uncertainty & $\theta_{E}$ & lognormal & 1.0 & 0.1 \\
\hline
\end{tabular}

295

\subsection{Reliability assessment}

The reliability assessment of structures can be performed using simulation-based methods or gradientbased methods [32]. Simulation-based approaches such as the Monte Carlo method [33] may result unviable, if the deterministic structural analysis is time-consuming and low probabilities of failure are expected. In gradient-based methods such as FORM [33], the limit state function is approximated by a linear function in a normalized space at the design point vicinity, but insufficient (and thus unacceptably low) accuracy can result from strong nonlinear limit state functions. To overcome these problems different techniques to approximate complex and implicit limit state functions have been proposed and used with both simulation and gradient based methods. Among these techniques, response surface methods (RSM), consisting of first and second order polynomials, have been widely used by different researchers [34], [35] to solve structural reliability problems. Artificial Neural Network (ANN) algorithms have also proved to be versatile and efficient in this scope [34]-[37], in particular for the approximation of large domains of non-linear performance functions [38].

For the reliability assessment of the case study different and combined techniques aiming at approaching the results of the numerical analysis to the real structural behavior were tested, to ensure the consistency and accuracy of the results obtained.

For the reliability analysis, Monte Carlo simulation, as well as the First Order Reliability Method (FORM), were used. These techniques were combined with the Response Surface Method (RSM) and the Artificial Neural Network (ANN) in order to obtain a fast approach of the structural behaviour, given by 
315 the structural analysis, and also to facilitate the reliability assessment by reducing the number of 316 numerical analysis to be performed.

317 The limit state function, G, used for the reliability analysis was defined as follows:

$$
G=\alpha \cdot \theta_{R}-\theta_{E}
$$

where $\alpha$ is the structural performance function, which depends on the defined random variables, $\alpha\left(f_{c}, f_{y}, f_{m}, g, g_{1}, q_{s}, q_{i}\right)$. It corresponds to the ratio between the resisting and the acting loads on the structure of the building, obtained following a pushdown numerical analysis. As mentioned, $\alpha$ needed to be approximated by an ANN algorithm in order to reduce the number of numerical analyses vs. the number of MC simulations. The probability of failure, $P_{f}$, was then computed as the ratio between failed simulations, defined by $G<0$, and the total number of simulations, and the reliability index resulted as $\beta=-\Phi^{-1}\left(P_{f}\right)$

The MATLAB software [39] was used to construct two ANN algorithms of the multi-layer feed forward type to simulate the damaged structure and the original (undamaged) structure. For the former, a 4456 size sample of the random variables $\left(f_{c}, f_{y}, f_{m}, g, g_{1}, q_{s}, q_{i}\right)$ was generated and for each sample's element the nonlinear analysis was performed. A large range of the $f_{m}$ random variable was considered, in order to observe the effect and importance of the masonry's mechanical properties on the structural safety. The ANN algorithm was trained, validated, and then tested considering respectively $75 \%, 15 \%$, and $10 \%$ of the total data set chosen randomly. In this case, Levenberg-Marquardt back propagation algorithm [40] was used to train the network was used. The architecture of the ANN for the damaged structure is depicted in

Figure 8. The number of neurons used to define the ANN was selected in order to obtain the best fit when comparing the output values with the target values. The network defined with 20 neurons resulted in the minimum error. The input layer had six neurons, corresponding to the input variables, and the output layer had just one neuron corresponding to the structural performance function. Since both the sustained,

$338 q_{S}$, and intermittent, $q_{i}$, loads produce the same loading effect a single input variable, $q$, was used to train the ANN. A mean square error equal to $9.8 \times 10^{-4}$ and $7.5 \times 10^{-4}$ was obtained for the validation and 
testing phases, respectively. It is worth mentioning that selection of a network optimal architecture is not

341 a simple task. The number of neurons and layers, including the size of the data used to train, validate and test the ANN, are in general determined based on a trial-and-error-process [32].

343 The same type of ANN was used to approach the load carrying capacity of the original (undamaged)

344 structure (see

345 Figure 8). As mentioned, the contribution of the masonry infill walls was not included in this model. A 346 mean square error bellow $10^{-5}$ was obtained for both the validation and testing phases, using only a 200 347 size sample.

348 The FORM method was used in parallel with the MC simulation to obtain the probability of failure and the reliability index, including the design point and the respective direct cosines, which provide the relative weight of each random variable to structural safety. Two different formulations of the FORM, named method 1 and method 2, were adopted [33], depending on the process used to estimate the derivatives of the limit state function. Method 1 considers an explicit definition of the latter, which allow its analytic derivation. In this case, the limit state function is approached using the RSM and a linear polynomial, defined in the design point neighborhood, and redefined at each iteration of the method for improved accuracy. The support points, required for the polynomial definition, are obtained through direct structural analysis or, alternatively, obtained indirectly using the ANN. Method 2, uses centred finite differences to determine the partial derivatives of the limit state function. In this case, the trained ANN was used to approach structural response to allow the assessment of the finite differences. Table 2 summarizes the different reliability methods used in this study. 


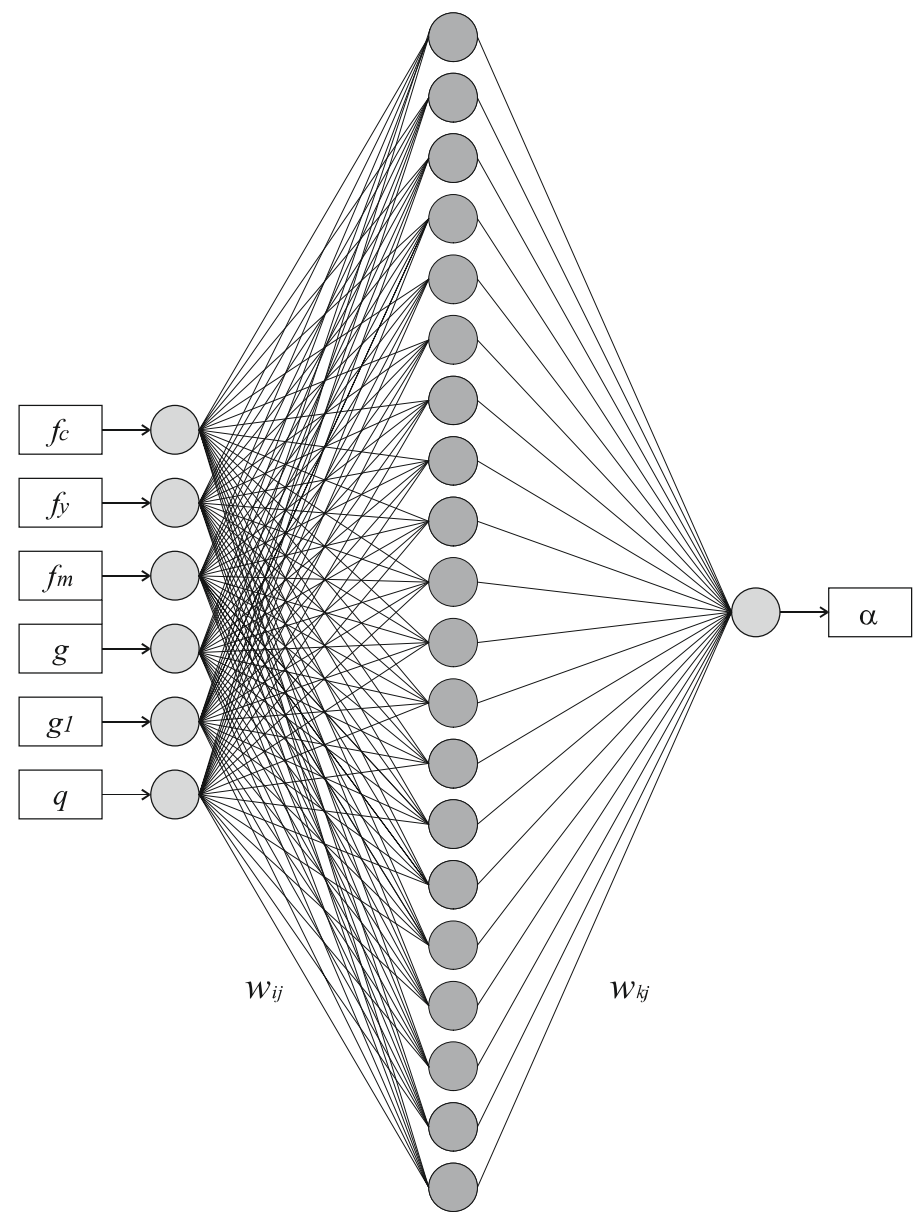

Figure 8 - Architecture of the ANN for the damaged structure.

Table 2 - Reliability Methods

\begin{tabular}{|c|c|c|}
\hline Method & $\begin{array}{l}\text { Reliability } \\
\text { method }\end{array}$ & $\begin{array}{c}\text { Structural performance } \\
\text { approximation }\end{array}$ \\
\hline MC/ANN & MC Simulation & Artificial Neural Network \\
\hline FORM1/RSM & FORM method 1 & Response surface method \\
\hline FORM1/RSM+ANN & FORM method 1 & $\begin{array}{c}\text { Response surface method } \\
+ \\
\text { Artificial Neural Network }\end{array}$ \\
\hline FORM2/FD+ANN & FORM method 2 & $\begin{array}{c}\text { Centred finite differences } \\
+ \\
+ \\
\text { Artificial Neural Network }\end{array}$ \\
\hline
\end{tabular}




\section{$362 \quad$ 5. Results and Discussion}

363 The reliability analysis was carried out taking into account the variables presented in Table 1 and using 364 the different safety methods presented in Table 2. Results obtained for the damaged structure considering 365 the effect of the masonry infill walls are presented in Table 3 for load cases 1 and 2. Results are referred 366 to a period of one year. The annual probability of failure and the reliability indexes were also derived reflecting the average occurrence of both load cases in the same period. $10^{6}$ simulations were used to ensure a reduced coefficient of variance for the probability of failure. It is worth mentioning that, for the damaged structure, when the contribution of the masonry infill walls is neglected, the probability of failure resulted approximately equal to $100 \%$, corroborating the results presented in [7].

Results of MC/ANN approach are conservative in comparison to those of FORM1/RSM, FORM1/RSM+ANN and FORM2/FD+ANN approaches, reflecting the different nature (simulation vs gradient) of the methods used. By comparing the results obtained with the gradient-based approaches, it can be stated that both the RSM and the ANN provide similar approximations in terms of accuracy for the structural performance function. In addition, there are no significant differences between results obtained with FORM method 1 or method 2. Although load case 1 is associated with a higher probability of failure, due to the simultaneous action of both live loads, load case 2, corresponding to the sustained live load acting alone, is critical in the assessment of the annual probability of failure, due to the higher occurrence rate.

Results in Table 3 show that the probability of failure of the damaged structure considering the effect of the masonry infill walls ranges from $3.60 \%$ to $6.07 \%$. These values correspond to reliability indexes varying between 1.80 and 1.55 , which, although not being acceptable for structures in service, clearly explain why the building did not collapse after the accident. They also provide a valuable quantitative measure of the safety conditions during the repairing and retrofitting period that followed. 


\begin{tabular}{cccc}
\hline \multirow{2}{*}{ Reliability Method } & Case & $P_{f} \mathbf{( \% )}$ & $\beta$ \\
& & & \\
\hline \multirow{2}{*}{ MC/ANN } & 1 & 7.45 & 1.44 \\
& 2 & 6.07 & 1.55 \\
& $1+2$ & $\mathbf{6 . 0 7}$ & $\mathbf{1 . 5 5}$ \\
\cline { 2 - 4 } FORM1/RSM & 1 & 5.23 & 1.62 \\
& 2 & 4.12 & 1.74 \\
FORM1/RSM+ANN & 2 & 3.61 & 1.80 \\
& $1+2$ & $\mathbf{4 . 1 2}$ & $\mathbf{1 . 7 4}$ \\
\cline { 2 - 4 } & $1+2$ & $\mathbf{3 . 6 0}$ & $\mathbf{1 . 8 0}$ \\
\cline { 2 - 4 } FORM2/FD+ANN & 1 & 4.88 & 1.66 \\
& 2 & 3.59 & 1.80 \\
& $1+2$ & $\mathbf{3 . 5 8}$ & $\mathbf{1 . 8 0}$ \\
\hline
\end{tabular}

389 Table 4 provides the probability of failure of the original (undamaged) structure, computed using the 390 MC/ANN method. Due to the expected lower probability of failure of the latter, the number of 391 simulations was increased up to $10^{9}$.

Table $4-P_{f}$ and $\beta$ for the undamaged structure

\begin{tabular}{cccc}
\hline Structure & Case & $P_{f}(\mathbf{\%})$ & $\beta$ \\
\hline \multirow{2}{*}{ undamaged } & 1 & $6.2 \times 10^{-6}$ & 5.29 \\
& 2 & $3.6 \times 10^{-6}$ & 5.37 \\
& $1+2$ & $\mathbf{3 . 6}^{-6} \mathbf{1 0}^{-6}$ & $\mathbf{5 . 3 7}$ \\
\hline
\end{tabular}

395 The probability of failure and the reliability index of the original (undamaged) structure resulted equal to $3963.6 \times 10^{-8}$ and 5.37 respectively. It is worth mentioning that the computed reliability index is higher than 397 the value (4.7) prescribed by the Eurocode [41] for structures within the reliability class RC2, 398 consequences $\mathrm{CC} 2$, and a reference period of 1 year.

399 The robustness of the damaged structure, computed according to Equation (1) and considering the effect 400 of the masonry infill walls, resulted equal to $R=1.55 / 5.37=0.29$, thus corresponding to $29 \%$ of the 401 reliability of the original (undamaged) structure. Neglecting the contributions of masonry infill walls, 

the collapse following the landslide would be certain.

404 To highlight the role played by the masonry infill walls in the safety of the damaged structure, Figure 9 and Figure 10 show the influence of the mean value of the masonry compressive strength, on the probability of failure and reliability index, respectively. Calculations were performed using both the simulation (MC/ANN) and the gradient-based approaches (FORM1/RSM/ANN and FORM2/FD+ANN).

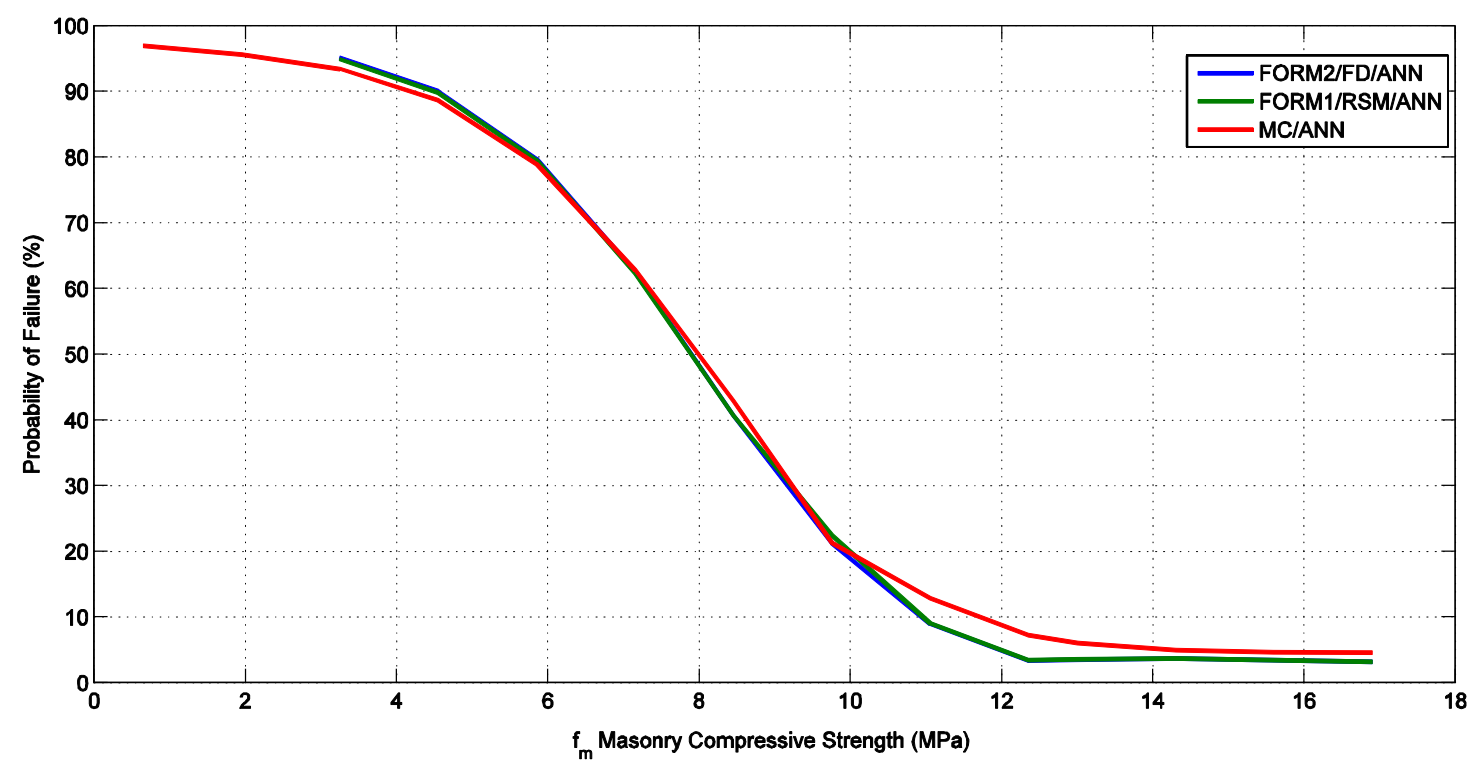

Figure 9 - Effects of the mean value of the masonry compressive strength to the damaged building probability of 408

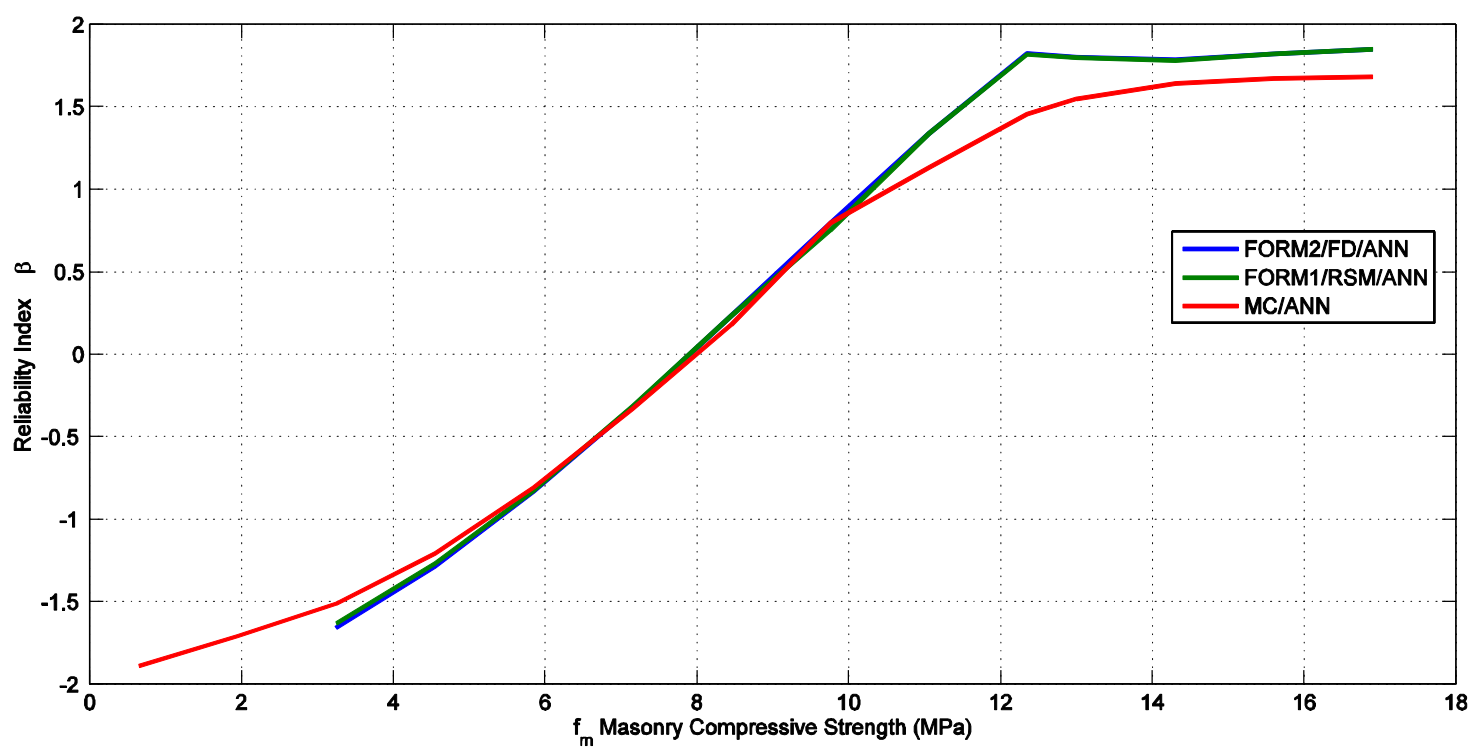

Figure 10 - Effects of the mean value of the masonry compressive strength to the damaged building reliability. 
410 Results in Figure 10 show that the probability of failure decreases as the mean value of the compressive

411 strength of the masonry increases up to $14 \mathrm{MPa}$. This is particularly evident for masonry compressive 412 strengths within the range of $5 \mathrm{MPa}$ to $10-11 \mathrm{MPa}$. For lower values, the material is too weak and

413 therefore the masonry equivalent strut does not provide a significant alternative load path to the $\mathrm{RC}$

414 structure. For higher values, and in particular above $14 \mathrm{MPa}$, results do not show significant increase of 415 the damaged building's safety with the increase of the masonry compressive strength. The structural 416 analysis showed that too strong masonry infill walls do not increase the load-bearing capacity of the damaged RC frame, as structural collapse is mainly controlled by the RC frame failure. Results presented in Figure 11 show the square of the direction cosines, which translate the relative importance of each random variable to the global safety. These results were obtained with FORM1/RSM+ANN method for critical load case 2 . As observed, for compressive strengths up to aproximatelly $90 \%$ of the average value (11-12 MPa), the uncertainity related to the masonry infill walls is critical for the safety of the damaged structure. Above these values, the steel yield strength random square cosine shows a significant increase, meaning that, for higher values of the compressive strength of the masonry, the structural collapse in mainly controlled by the failure of the RC elements. Figure 11 also shows that uncertainties related to the strength and load models are of paramount importance in the assessment of the damaged structure reliability.

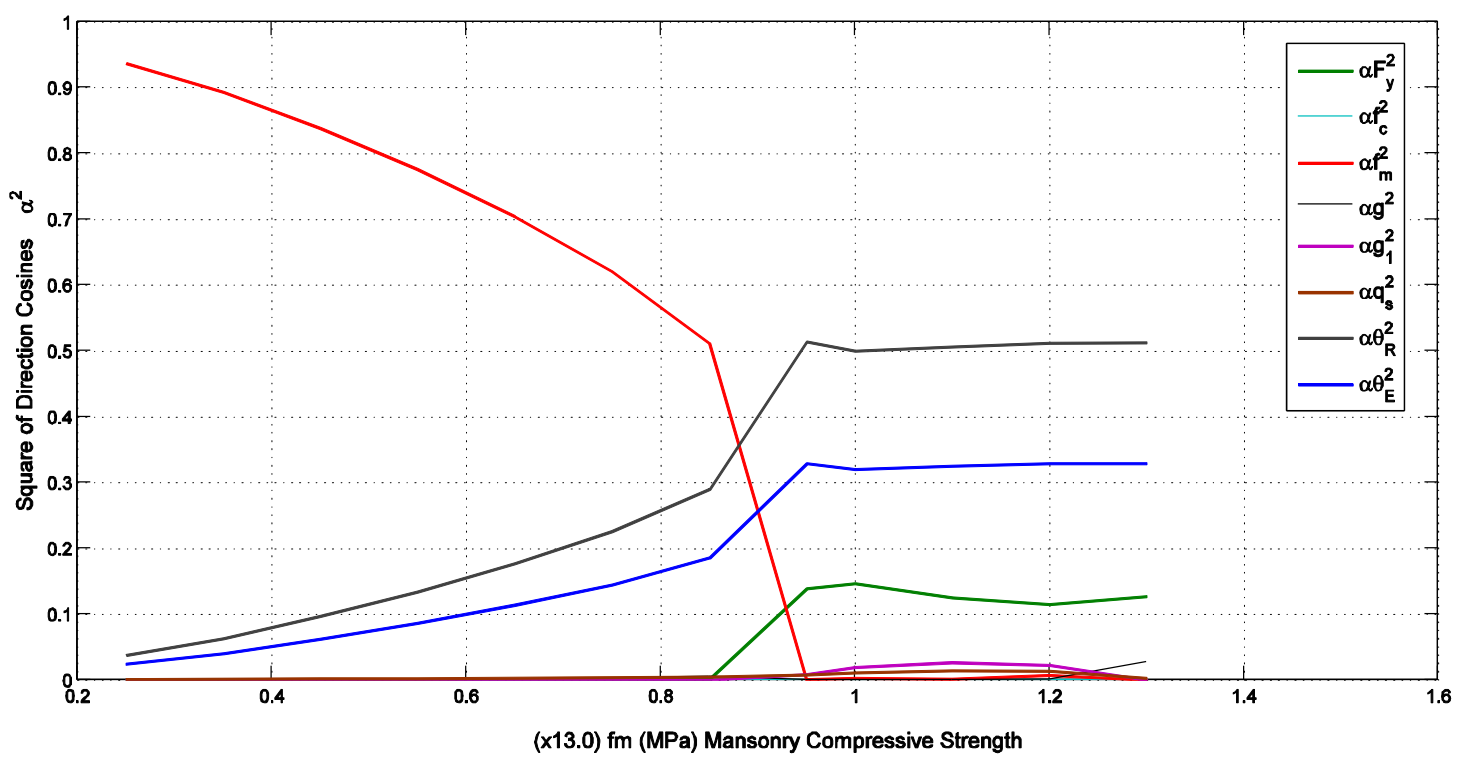

Figure 11 - Effects of the mean value of masonry compressive strength at the square of direction cosines. 


\section{Conclusions}

The contribution of the masonry infill walls to the robustness of framed RC structures was investigated in this work by studying in detail a real building subjected to severe damage. Robustness was defined as the ratio between the reliability index of the damaged structure and the corresponding value of the original undamaged structure. The contribution of the masonry infill walls was either neglected or considered by means of an equivalent strut. The following conclusions can be drawn:

1. Even when neglecting the contribution of the masonry infill walls, the original undamaged structure exhibits an adequate safety level, with a reliability index equal to 5.4, thus significantly above the minimum recommended value in the Eurocode $\left(\beta_{\text {target }}=4.7\right)$;

2. When neglecting the contribution of the masonry infill walls, the structural robustness of the damaged structure is null, with a probability of failure very close to $100 \%$;

3. Considering the contribution of the masonry infill walls, robustness is increased to $29 \%$ and the corresponding probability of having a global structural failure is reduced to $6 \%$; this result clearly explains the survival of the damaged structure.

4. A sensitive analysis showed that the safety of the damaged structure is mainly dependent on the compressive strength of the masonry wall and by the yield stress of the steel bars of the RC cantilever beams. Below $5 \mathrm{MPa}$, the masonry infill walls are too weak and thus safety relies on the RC cantilevers. Likewise, above 11-12 MPa, the masonry infill walls are too strong and an increase in their compressive strength does not change the structure's safety, which depends again on the RC structure. Between the values referred to, the higher the compressive strength of the masonry infill walls, the safer the damaged structure is.

\section{Acknowledgments}

The authors acknowledge funding provided by Portugal 2020 under the grant 02/SAICT/2017, project PROTEDES - Protection of strategic building against blast actions.

\section{References}

[1] Cynthia Pearson and Norbert Delatte, "Ronan Point Apartment Tower Collapse and its Effect on Building Codes," J. Perform. Constr. Facil., vol. 19, no. 2, pp. 172-177, 2005.

[2] Z. P. Bazant and Y. Zhou, "Why did World Trade Center collapse?-Simple analysis," Arch. Appl. Mech., vol. 71, no. 12, pp. 802-806, 2001. 
[3] P. Tiago and E. Júlio, "Case study: Damage of an RC building after a landslide - inspection, analysis and retrofitting," Eng. Struct., vol. 32, no. 7, pp. 1814-1820, Jul. 2010.

[4] E. S. Cavaco, J. R. Casas, L. A. Neves, and A. E. Huespe, "Robustness of corroded reinforced concrete structures-a structural performance approach," Struct. Infrastruct. Eng., vol. 9, no. 1, pp. 42-58, 2013.

[5] C. Murty and S. K. Jain, "Beneficial influence of masonry infill walls on seismic performance of RC frame buildings," in 12th World Conference on Earthquake Engineering (Auckland, New Zealand, January 30), 2000.

[6] P. Asteris, "Lateral stiffness of brick masonry infilled plane frames," J. Struct. Eng., vol. 129, no. 8, pp. 1071-1079, 2003.

[7] S. Sattar and A. B. Liel, "Seismic performance of reinforced concrete frame structures with and without masonry infill walls," in 9th US National and 10th Canadian conference on earthquake engineering, 2010.

[8] S. Pujol, A. Benavent-Climent, M. E. Rodriguez, and J. P. Smith-Pardo, "Masonry infill walls: an effective alternative for seismic strengthening of low-rise reinforced concrete building structures," in 14th World Conference on Earthquake Engineering (Beijing, China, Unknown Month October 12), 2008.

[9] L. M. Abdel-Hafez, A. E. Y. Abouelezz, and F. F. Elzefeary, "Behavior of masonry strengthened infilled reinforced concrete frames under in-plane load," HBRC J., vol. 11, no. 2, pp. 213-223, Aug. 2015.

[10] G. Al-Chaar, "Evaluating strength and stiffness of unreinforced masonry infill structures," US Army Corps of Engineers, Engineer Research and Development Center, Construction Engineering Research Laboratory, 2002.

[11] G. Al-Chaar, "Non-ductile behavior of reinforced concrete frames with masonry infill panels subjected to in-plane loading," DTIC Document, 1998.

[12] F. J. Crisafulli, A. J. Carr, and R. Park, "Analytical modelling of infilled frame structures - A general review," Society for Earthquake Engineering, New Zealand, 2000.

[13] G. Al-Chaar and D. Abrams, "Parametric Studies on Seismic Behavior of Frame-Infill Systems," in Proceedings of the Ninth Canadian Masonry Symposium, 2001.

[14] G. Al-Chaar, G. Lamb, and D. Abrams, "Seismic Behavior of a Multistory and Multibay FrameInfill System," in Proceedings of the Ninth Canadian Masonry Symposium, 2001.

[15] W. W. El-Dakhakhni, M. Elgaaly, and A. A. Hamid, "Three-Strut Model for Concrete MasonryInfilled Steel Frames,” J. Struct. Eng., vol. 129, no. 2, pp. 177-185, Feb. 2003.

[16] P. G. Asteris, "Numerical Investigation of the Effect of Infill Walls on the Structural Response of RC Frames," Open Constr. Build. Technol. J., vol. 6, no. 1, pp. 164-181, Oct. 2012.

[17] P. G. Asteris, I. P. Giannopoulos, and C. Z. Chrysostomou, "Modeling of Infilled Frames With Openings," Open Constr. Build. Technol. J., vol. 6, no. 1, pp. 81-91, Oct. 2012.

[18] P. G. Asteris, C. Z. Chrysostomou, and I. P. Giannopoulos, "MASONRY INFILLED REINFORCED CONCRETE FRAMES WITH OPENINGS," in Proc 3rd international conference on computational methods in structural dynamics and earthquake engineering, Greece, 2011, p. 15.

[19] P. G. Asteris, D. M. Cotsovos, C. Z. Chrysostomou, A. Mohebkhah, and G. K. Al-Chaar, "Mathematical micromodeling of infilled frames: State of the art," Eng. Struct., vol. 56, pp. 19051921, Nov. 2013.

[20] P. G. Asteris, L. Cavaleri, F. Di Trapani, and V. Sarhosis, "A macro-modelling approach for the analysis of infilled frame structures considering the effects of openings and vertical loads," Struct. Infrastruct. Eng., vol. 12, no. 5, pp. 551-566, May 2016.

[21] M. Sasani, "Response of a reinforced concrete infilled-frame structure to removal of two adjacent columns,” Eng. Struct., vol. 30, no. 9, pp. 2478-2491, Sep. 2008.

[22] Cachado, A, Grilo, I, Júlio, E, and Neves, L, "Use of Non-Structural Masonry Walls as Robustness Reserve," in IABSE-IASS Symposium-Taller, Longer, Lighter, London, UK, 2011.

[23] S. Farazman, B. A. Izzuddin, and D. Cormie, "Influence of Unreinforced Masonry Infill Panels on the Robustness of Multistory Buildings," J. Perform. Constr. Facil., Sep. 2012.

[24] F. Xavier, L. Macorini, and B. Izzuddin, "Robustness of multistory buildings with masonry infill," J. Perform. Constr. Facil., vol. 29, no. 5, p. B4014004, 2014.

[25] H. Helmy, H. Hadhoud, and S. Mourad, "Infilled masonry walls contribution in mitigating progressive collapse of multistory reinforced concrete structures according to UFC guidelines," Int. J. Adv. Struct. Eng. IJASE, vol. 7, no. 3, pp. 233-247, Sep. 2015.

[26] Department of Defense, USA, Design of Structures to Resist Progressive Collapse. 2013.

[27] E. Cavaco, L. A. C. Neves, and J. R. Casas, "Reliability-based approach to the robustness of corroded reinforced concrete structures," Struct. Concr., vol. 18, no. 2, pp. 316-325, Apr. 2017. 
[28] S. Mazzoni, F. Mckenna, M. H. Scott, and G. L. Fenves, Opensees command language manual. Berkeley: Pacific Earthquake Engineering Research Center, 2015.

[29] Imprensa Nacional and Casa da Moeda, Regulamento de Estruturas de Betão Armado e Préesforçado. 1983.

[30] T. Vrouwenvelder, "The JCSS probabilistic model code," Structural Safety, vol. 19. pp. 245-251, 1997.

[31] R. Vicente, "Patologia Paredes Fachada. Estudo do comportamento mecânico das paredes de fachada com correcção exterior das pontes térmicas.," MSc thesis, FCT-Universidade de Coimbra, Coimbra, 2002.

[32] A. A. Chojaczyk, A. P. Teixeira, L. C. Neves, J. B. Cardoso, and C. Guedes Soraes, "Review and application of Artificial Neural Networks models in reliability analysis of steel structures," Struct. Saf., 2014.

[33] A. Haldar and S. Mahadevan, Probability, reliability, and statistical methods in engineering design. John Wiley \& Sons, Incorporated, 2000.

[34] H. M. Gomes and A. M. Awruch, "Comparison of response surface and neural network with other methods for structural reliability analysis," Struct. Saf., vol. 26, pp. 49-67, 2004.

[35] A. Hosni Elhewy, E. Mesbahi, and Y. Pu, "Reliability analysis of structures using neural network method," Probabilistic Eng. Mech., vol. 21, no. 1, pp. 44-53, Jan. 2006.

[36] A. T. Goh and F. H. Kulhawy, "Neural network approach to model the limit state surface for reliability analysis," Can. Geotech. J., vol. 40, no. 6, pp. 1235-1244, Dec. 2003.

[37] M. Papadrakakis, V. Papadopoulos, and N. D. Lagaros, "Structural reliability analyis of elasticplastic structures using neural networks and Monte Carlo simulation," Comput. Methods Appl. Mech. Eng., vol. 136, no. 1, pp. 145-163, Sep. 1996.

[38] J. B. Cardoso, J. R. de Almeida, J. M. Dias, and P. G. Coelho, "Structural reliability analysis using Monte Carlo simulation and neural networks," Adv. Eng. Softw., vol. 39, no. 6, pp. 505-513, Jun. 2008.

[39] D. Hanselman, B. Littlefield, and C. S. A. Martins, Matlab 6: curso completo. Prentice Hall, 2003.

[40] J. J. Moré, "The Levenberg-Marquardt algorithm: implementation and theory," in Numerical analysis, Springer, 1978, pp. 105-116.

[41] CEN, "EN 1990: Eurocode: Basis of Structural Design," Bruss. Belg. Eur. Norm., 2002. 